http://jmscr.igmpublication.org/home/

ISSN (e)-2347-176x ISSN (p) 2455-0450

crossref DOI: https://dx.doi.org/10.18535/jmscr/v7i8.167

Journal Of Medical Science And Clinical Research

IGM Publication

An official Publication of IGM Publication

\title{
Clinico-pathological profile of hepatic involvement in type 2 diabetes mellitus patients attending tertiary care hospital in Maharashtra
}

\author{
Authors \\ Dr Harshal Bhitkar ${ }^{1}$, Dr Santosh Thorat ${ }^{2}$ \\ ${ }^{1}$ Associate Professor, Dept of Medicine, B J Govt Medical College Pune, India \\ ${ }^{2}$ Assistant Professor, Department of General Surgery, B J Medical College Pune, India
}

\section{Introduction}

Liver is the principle organ for degradation of insulin. In type 2 diabetes mellitus spectrum of liver changes occurs from simple steatosis (NAFL), non-alcoholic steatohepatitis (NASH) ,cirrhosis to hepatocellular carcinoma . These all diseases are included in common entity as nonalcoholic fatty liver disease (NAFLD) ${ }^{1}$.

Most of the patients with type 2 diabetes mellitus have clinical characteristics of insulin resistance syndrome including obesity (visceral fat), hypertension, glucose intolerance and typically dyslipidemia $^{2}$. This obesity and insulin resistance have been strongly associated with NAFLD.

In most of instances NAFLD is silent disease so it is very much difficult to diagnose in early stages. NAFLD progresses very slowly however in $20 \%$ it progresses rapidly. Progression in NAFL to fibrosis stage 1 is every 14 years and every 7 years in NASH which is further increases in the presence of arterial hypertension. Cirrhosis and liver failure occurs in $11 \%$ to $20 \%$ NASH patients over 10 to 15 years $^{3}$.

There is 2.2 fold increases in overall mortality in NAFLD with the most common cause of death being cardiovascular diseases. Patient with NASH have an increased liver related mortality rate with decompensated liver failure and HCC corresponding to $2 \%$. The mortality rate of type 2 diabetes mellitus patients due to cirrhosis is more than twice the general population, further more they tend to have poor prognosis with high rate of cirrhosis and mortality ${ }^{3}$.

In the modern era of metabolic syndrome as obesity and type 2 diabetes mellitus epidemic is growing NASH prevalence is also increasing from $30 \%$ to $60 \%$ in western population. It is expected to become leading cause of liver transplant by $2020^{4}$. In India also prevalence is also found to be around $60 \%$ in many studies.

Thus for the diagnosis of NAFLD requires high index of suspicion particularly in obese patient over age of 45 years with history of type 2 diabetes mellitus.

Present study was conducted to determine the Clinico-pathological profile of hepatic involvement in type 2 diabetes mellitus patients attending medicine opd at tertiary care hospital in Maharashtra.

\section{Material and Method}

In this prospective study, a total of 150 patients with T2DM study population was included the age group of 20-70 years, attending medical outpatient clinic from January 2018 to January 2019. A complete history taking and physical examination 
of type 2 diabetes mellitus patients attending medicine OPD were performed. approval from the Institutional Ethics Committee and informed consent from the patients taken. Physical measurement such as waist circumference, body mass index and metabolic parameters such as fasting and postprandial blood sugar, glycosylated haemoglobin (HbA1c), serum uric acid, blood urea, serum creatinine, fasting lipid profile, serum bilirubin, serum glutamic oxaloacetic transaminase (SGOT), serum glutamic pyruvic transaminase (SGPT) and serum alkaline phosphatase (SAP) were measured.

The patients who agreed for the participation in the study were screened by the USG abdomen with high resolution B mode system. On the basis of the USG abdomen and pelvis patients were stratified in the stage 1 , stage 2 , stage 3 according to mild moderate and severe steatosis.

Though for a precise diagnosis of NAFLD liver biopsy is the investigation of choice the sensitivity of USG in detection of hepatic steatosis ranges from 60 to $94 \%$ and specificity ranges from 84 to $95 \%{ }^{5}$.

Patients with chronic alcohol consumption, chronic liver disease due to any other aetiology were excluded.

Statistical analysis: Data documented and analysed using Statistical Package for Social Sciences [SPSS], Pearson's Chi Square Analysis test and Fisher exact probability test. Mean and standard deviation were calculated for each variable. The diabetic patients with fatty liver were compared with the diabetic patients without fatty liver.

\section{Results}

Total 150 patients with T2DM were recruited and their baseline characteristics are summarised in the following tables:

Table 1 Overall most of the patients were predominantly obese accounting for $65 \%$.

\begin{tabular}{|l|c|c|}
\hline Obese & Non-obese & Total \\
\hline $98(65 \%)$ & $52(35 \%)$ & 150 \\
\hline
\end{tabular}

Table 2 sex distribution

\begin{tabular}{|l|c|c|c|}
\hline Sex & NAFLD & NON-FALD & TOTAL \\
\hline MALE & $40(57 \%)$ & $30(43 \%)$ & 70 \\
\hline FEMALE & $47(59 \%)$ & $33(41 \%)$ & 80 \\
\hline
\end{tabular}

The male and female patient was found to have equal prevalence of NAFLD.

Mostly the patients 38\% were in the age group of 40 to 49 years.

Table 3 comparison of obese and non-obese patient in NAFLD

\begin{tabular}{|l|c|c|}
\hline & NAFLD & NON-NAFLD \\
\hline Obese & $74(75 \%)$ & $24(25 \%)$ \\
\hline Non-obese & $19(36 \%)$ & $33(64 \%)$ \\
\hline
\end{tabular}

Table 4 Population wise variables in respect to NAFLD with type2 DM

\begin{tabular}{|c|c|c|c|}
\hline & NAFLD & $\begin{array}{c}\text { NON- } \\
\text { NAFLD }\end{array}$ & P VALUE \\
\hline AGE (Mean \pm SD) & $\begin{array}{l}40-49 \\
\text { years }\end{array}$ & $\begin{array}{l}40-49 \\
\text { years }\end{array}$ & NS \\
\hline $\begin{array}{l}\text { FASTING } \\
(\text { Mean } \pm \text { SD })\end{array}$ & 160 & 100 & 0.004 \\
\hline HbA1c(Mean \pm SD) & 9 & 7 & $<0.0001$ \\
\hline $\begin{array}{l}\text { DM duration in years } \\
(\text { Mean } \pm \text { SD) }\end{array}$ & 8 & 2 & $<0.0001$ \\
\hline $\begin{array}{ll}\begin{array}{l}\text { Systolic } \\
(\text { Mean } \pm \text { SD) }\end{array} & \text { BP } \\
\end{array}$ & 128 & 138 & 0.02 \\
\hline $\begin{array}{ll}\begin{array}{l}\text { Diastolic } \\
(\text { Mean } \pm \text { SD })\end{array} & \text { BP } \\
\end{array}$ & 78 & 76 & 0.78 \\
\hline OHA use $($ Mean \pm SD) & $92 \%$ & $87 \%$ & 0.14 \\
\hline $\begin{array}{l}\text { Anti HT medications } \\
(\text { Mean } \pm \text { SD })\end{array}$ & $90 \%$ & $73 \%$ & 0.04 \\
\hline
\end{tabular}

Plasma cholesterol and triglyceride levels were found to be equal in both the group.

Table 5 severity amongst NAFLD patients

\begin{tabular}{|l|c|c|c|c|}
\hline & Mild & Moderate & Severe & total \\
\hline Male & 25 & 11 & 04 & 40 \\
\hline Female & 30 & 12 & 05 & 47 \\
\hline
\end{tabular}

\section{Discussion}

The occurrence of NAFLD is 9 to $40 \%$ in the Asian countries. In Our study the prevalence found to be $58 \%$ which is similar to the study done by Gupte et al $(65.5 \%)^{7}$.

Another Indian study done by the Chandel k et al showed nearly equal incidence of NAFLD in male and female patient similar to our study ${ }^{8}$. Also In our study the patients having increased BSL \& 
HbA1c were associated with the NAFLD. Similar findings were observed by the study done by Patel $\mathrm{H}$ et al and Karla $\mathrm{S}$ etal ${ }^{9,10}$.

In the study $63 \%$ the obese patients with diabetes were having mild NAFLD, 26\% were having moderate steatosis, $11 \%$ were having severe steatosis which is similar to the study by Gupte et al group. $(65.5 \%, 12.5 \%, 9.35 \%)$

\section{Conclusion}

Increasing prevalence of Type 2 DM \& NAFLD makes it a public health problem. Type $2 \mathrm{DM}$ is not only a risk factor but it also accelerates its progression. Thus in the presence of the obesity every diabetic patient should undergo evaluation for NAFLD. Also the Type $2 \mathrm{DM}$ must be controlled to prevent insulin resistance and viceversa NAFLD.

\section{References}

1. Banerjee S, Ghosh US, Dutta S. Clinicopathological profile of hepatic involvement in type-2 diabetes mellitus and its significance. JAPI. 2008;56(5):581 $-6$.

2. Portillo- Sanchez P et al .High prevalence of non alcoholic fatty liver disease in patients with type 2 diabetes mellitus and normal plasma aminotransferase levels. J ClinEndocrinol Metab. 2015 Jun ;100(6):2231-2238

3. Dharmalingum $M$ et al .Indian $\mathbf{J}$ Endocrinol Metab. 2018 May-Jun;22(3): 421-428

4. Estes, C. et al .modeling the epidemic of non alcoholic fatty liver disease demonstrates an exponential increase in burden of disease .2018 67(1):123-133

5. Saadeh S, Younossi ZM, Remer EM, Gramlich T, Ong JP, Hurley M, et al. The utility of radiological imaging in nonalcoholic fatty liver disease. Gastroenterol. 2002;30;123(3):745-50.
6. Adams LA, Lymp JF, St Sauver J, Sanderson SO, Lindor KD, Feldstein A, et al. The natural history of non-alcoholic fatty liver disease: a population based cohort study. Gastroenterol. 2005;129(1):113-21.

7. Gupte P, Amarapurkar D, Agal S, Baijal R, Kulshrestha P, Pramanik S, et al. Non- alcoholic steatohepatitis in type 2 diabetes mellitus. J Gastroenterol Hepatol. 2004;19(8):854-8

8. Chandel K.et al.A study of prevalence of non alcoholic fatty liver disease in type 2 diabetes mellitus. Panacea Journal of medical sciences, September-december, 2016;6(3):147-150.

9. Patel H.et al. prevalence of non alcoholic fatty liver disease in type 2 diabetes mellitus patients. Int J Res Med Sci.2018 Apr;6(4):1322-1326

10. KalraS, Vithalani, M, Gulati G, Kulkarni CM, Kadam Y, Pallivathukkal J, et al. Study of prevalence of non-alcoholic fatty liver disease (NAFLD) in type 2 diabetes patients in India(SPRINT). J Assoc Physicians India. 2013;61(7):448-53. 